\title{
El arte de contar cuentos y rendir cuentas. La revisión de las cuentas públicas del Gobierno de Sonora, 2004-2010
}

\author{
Oscar Nicasio Lagunes López* \\ Nicolás Pineda Pablos ${ }^{* *}$
}

Resumen: en este artículo se estudia la fiscalización de las cuentas públicas, de 2004 a 2010, en cinco dependencias del Gobierno de Sonora. La pregunta de investigación es qué tan efectiva es la fiscalización que realiza el Instituto Superior de Auditoría y Fiscalización, para combatir el uso indebido de los recursos públicos. Al revisar el marco legal, se encontró que el instituto carece de facultades para sancionar, y que esta es tarea de la Secretaría de la Contraloría General, una dependencia del mismo Ejecutivo. Por otra parte, al analizar las observaciones, solventaciones y sanciones incluidas en los informes de resultados presentados por el instituto, se encontró que la Oficina del Ejecutivo queda exenta de observaciones, y que en el resto de las dependencias el número de éstas aumentó, mientras que el de las solventadas tendió a decrecer durante el periodo. Por último, no hay información que vincule las observaciones no solventadas con las sanciones aplicadas por la Contraloría. La conclusión general es que, debido al diseño estructural

\footnotetext{
* Estudiante del doctorado en ciencias sociales de El Colegio de Sonora. Correo electrónico: oscar_lagunes@hotmail.com

** Investigador de El Colegio de Sonora. Correo electrónico: npineda@colson.edu.mx
} 
de la fiscalización que regresa al ámbito del Ejecutivo para la aplicación de sanciones, la fiscalización del instituto, si bien inhibe el mal uso de los recursos en los ámbitos operativos de la administración estatal, no impide ni evita la malversación de fondos de alto nivel.

Palabras clave: fiscalización, cuenta pública, rendición de cuentas, corrupción, sanciones, Gobierno de Sonora, México.

Abstract: this article examines the oversight of public accounts in five agencies of the Sonora State Government between 2004 and 2012. The research question is how effective is the audit carried out by the Superior Institute of Audit and Inspection (ISAF) in combatting the misuse of public resources. Upon reviewing the legal framework, we found that ISAF does not have the power to sanction; this activity is carried out by the State General Comptroller, an office that reports to the Executive. Moreover, an analysis of the observations, resolutions and sanctions mentioned in performance reports presented by ISAF showed that, during the period studied, no observations at all were made to the Office of the Executive and that, in other government agencies, the number of observations increased, but the number of those resolved decreased. Finally, there is no information linking unresolved observations to the sanctions applied by the office of the Comptroller. The general conclusion is that, due to the structural design of the oversight process, which turns the application of sanctions over to the Executive Power, the audits carried out by ISAF, although they inhibit the misuse of resources in the lower levels of the state administration, do not prevent embezzlement of funds in the upper levels.

Key words: public audit, public account, accountability, corruption, sanctions, Government of Sonora, Mexico. 


\section{Introducción}

En lo que va del siglo xxi, México ha logrado contar con elecciones relativamente libres y competidas, pero no con procesos efectivos de rendición de cuentas. Esta deficiencia del proceso de transición democrática es notoria en las entidades federativas donde se aprecia que, gracias al debilitamiento del presidencialismo, los gobiernos estatales se han convertido en feudos donde los gobernadores constituyen "poderes fácticos aislados de la ciudadanía, carentes de obligación de rendir cuentas y, para todo fin práctico, sin contrapeso alguno" (Rubio 2011, 33).

Este trabajo aborda un aspecto concreto, pero central de la rendición de cuentas, que es la fiscalización de las cuentas públicas en el estado de Sonora. La problemática que sirve de punto de partida es que el gobierno estatal cuenta con un mecanismo denominado “fiscalización”, cuya función de jure es evitar la malversación de los recursos públicos. Sin embargo, de facto hay una percepción amplia y generalizada de que dicha fiscalización no funciona; que algo está haciéndose mal, aunque en apariencia sea transparente y eficiente. Aunque existen procesos electorales competitivos y libres en el ejercicio del poder, los nuevos gobiernos democráticos tienden a reproducir prácticas añejas heredadas de los regímenes autoritarios, como el clientelismo, el sigilo burocrático, la corrupción y arreglos por debajo de la mesa de asuntos públicos (Olvera e Isunza 2004).

El objetivo es analizar la función fiscalizadora del Instituto Superior de Auditoría y Fiscalización (ISAF) del Gobierno de Sonora, durante el periodo 2004 a 2010, en específico las observaciones que se hacen en materia de la aplicación o uso indebido de los recursos públicos de los sujetos obligados. La pregunta principal es ¿qué tan efectiva es la función fiscalizadora que realiza el ISAF en la tarea de combatir la corrupción, entendida esta como la malversación de fondos públicos? Para contestarla, se analizan los informes de resultados de la revisión de las cuentas públicas de una muestra de dependencias de la administración estatal en dicho lapso. Primero se revisa el marco legal e institucional de la rendición de cuentas, luego las observaciones hechas a éstas y, en el último apartado, se 
hacen algunas reflexiones y consideraciones generales sobre el proceso estudiado.

El contexto político en el cual se lleva a cabo la fiscalización objeto del presente estudio se divide en dos periodos; el primero, de 2003 a 2009, en el que hubo gobierno unificado, es decir, el Poder Ejecutivo estuvo depositado en un gobernador emanado del Partido Revolucionario Institucional (PRI), y tuvo mayoría simple en el Congreso del estado, aunque no alcanzó la mayoría calificada durante las dos legislaturas de este sexenio. Y en el segundo, iniciado en septiembre de 2009, hubo alternancia en el partido del gobernador, pues surgió del Partido Acción nacional (PAN), mientras que en el Congreso la denominada alianza del PRI, Partido Nueva Alianza (PANAL) y el Partido Verde Ecologista de México (PVEM) tenía la mayoría simple y el pan era minoría. Esta variación en el contexto político resulta relevante y le añade interés a este estudio, ya que permite ver si en el último año, el de la alternancia, la fiscalización de las cuentas públicas resulta diferente de las anteriores.

Breve repaso de los conceptos de rendición de cuentas, fiscalización y cuenta pública

El concepto de la rendición de cuentas está vinculado a la teoría de la democracia, y según Ugalde $(2003,9)$ se define como "la obligación permanente de los mandatarios o agentes para informar a sus mandantes o principales de los actos que llevan a cabo como resultado de una delegación de autoridad que se realiza mediante un contrato formal o informal y que implica sanciones en caso de incumplimiento. Los mandantes o principales supervisan también a los mandatarios o agentes para garantizar que la información proporcionada sea fidedigna”.

Esta definición contiene tres elementos esenciales que conforman la estructura básica del proceso de rendición de cuentas (Schedler 2004, 20), y sin los cuales no podría entenderse: a) el sujeto o los sujetos que rinden cuentas: los funcionarios públicos; b) el sujeto o los sujetos a quienes se les rinde cuentas: Congreso del estado, el órgano técnico del Congreso, las contralorías fiscalizado- 
ras y grupos que representan a la sociedad civil e individuos y c) la evaluación o juicio al desempeño de los funcionarios públicos: calificación, penas y sanciones, que aplicarán las instancias correspondientes al ejercicio de la función pública. El tercer elemento es clave, y le da sentido a todo el proceso, puesto que la ausencia de calificación, sanciones o castigos hace que no exista una verdadera rendición de cuentas, que carecería de sentido sin penas y sanciones a los funcionarios del gobierno por usar los recursos públicos, con fines distintos a los de la ley. La finalidad mínima y esencial de este mecanismo es disminuir y, en la medida de lo posible, evitar una de las prácticas más comunes de la corrupción en México: la malversación de los recursos o fondos públicos y el uso de los bienes públicos para el beneficio privado.

Por su parte, O’Donnell (1997, 2 y 13) habla de la rendición de cuentas vertical y horizontal, según se lleve a cabo por medio de elecciones o desde la sociedad civil, o bien por procesos y órganos internos.

Con frecuencia la rendición de cuentas se interpreta como un mero informe de contabilidad, centrado en las sumas y gastos del presupuesto. Sin embargo, en sentido más amplio designa "el proceso por el cual los funcionarios públicos y gobernantes deben informar y explicar sus decisiones y actos de gobierno, de tal manera que se hagan responsables del ejercicio de la autoridad pública que les fue conferida de manera contractual" (Del Castillo 2003, 12). De este modo, la rendición de cuentas no sólo se refiere a los datos numéricos y los gastos, sino también a la explicación y justificación de las decisiones que se toman, así como los logros y metas alcanzadas. Los criterios que se utilizan con más frecuencia para evaluarla son: la eficacia, la eficiencia, la equidad, la transparencia, la honradez y la legalidad, que aseguran una correcta administración de los recursos públicos (Dunn 1994, 283).

Ahora bien, la fiscalización consiste en determinar la legalidad y la honestidad en el manejo de los fondos públicos. Ésta puede ser interna, si se realiza dentro de la misma administración del Ejecutivo, y externa si está a cargo de la Legislatura, el Poder Judicial y el pueblo (Muñoz Amato 1978, 192). Y su objetivo es contribuir a identificar los errores u omisiones, con el fin de disminuir o reducir los actos de corrupción dentro de la administración pública, 
implementando para ello mecanismos que garanticen la utilización correcta de los fondos públicos (Jiménez 2008).

Es importante tener claro el concepto de cuenta pública, que es específicamente el objeto de estudio de este trabajo, y se entiende como "un reporte anual previsto por las leyes mexicanas para que los gobiernos informen sobre el origen de sus ingresos, el destino de sus gastos y las razones de sus decisiones; así como para que el poder legislativo realice su función de fiscalización y vigilancia de los fondos públicos" (Pineda et al. 2007, 100). Por medio de este reporte anual, los tres niveles de gobierno dan a conocer al Congreso los resultados obtenidos durante un año de su gestión, en relación con el presupuesto aprobado, el gasto ejercido y las metas logradas. No obstante, las cuentas públicas no se reducen a un procedimiento aritmético de verificación ingreso-egreso, sino que son también una construcción interpretativa de la realidad dentro del proceso de rendición de cuentas, en el que intervienen actores con intereses y valores distintos.

La finalidad de las cuentas públicas en las democracias modernas es presentar "una historia de la intención humana y agencia que envuelven a los funcionarios públicos y a los políticos, y que conducen a que estos individuos sean responsables" (March y Olsen 1995, 150). Pineda et al. (2007) proponen tres estratos de desarrollo institucional de la revisión de las cuentas públicas: el autoritario, el democratizante y el democrático. En el primero, por lo general, no existe una verdadera rendición de cuentas, y si la hay es una mera simulación, puesto que la información sólo está disponible para el Estado, es decir, no es pública y el proceso se realiza como rito protocolario, sin una fiscalización auténtica. La falta de sanciones y castigo a los desvíos de fondos públicos para fines privados, la ineficiencia e ineficacia del gasto y la discrecionalidad de los funcionarios respecto al incumplimiento de su deber y al de sus subordinados son notas distintivas de este estrato. Además, en esta etapa tampoco hay grupos autónomos y personas que vigilen y revisen la cuenta pública.

El democratizante constituye una etapa de transición entre la simulación o la rendición aparente de cuentas y la verdadera, o lo que es lo mismo, entre el estrato autoritario y el democrático. En este caso, la información puede ser presentada con ciertas deficiencias. No 
obstante, su contenido se hace más comprensible y accesible a la ciudadanía y se busca aplicar sanciones. Es notoria la ausencia de un entorno social que vigile, revise, discuta y sancione de modo independiente y colectivo las cuentas del gobierno.

En el estrato democrático la información es clara y accesible a cualquier ciudadano; los desvíos de fondos públicos y otros delitos relacionados con el cargo de los funcionarios son sancionados y castigados; hay pluralidad de grupos independientes, organizaciones civiles e individuos que vigilan, discuten, evalúan y sancionan el ejercicio de la cuenta pública y el progreso de los programas implementados por el gobierno.

En resumen, la rendición de cuentas, en general, y la revisión de las cuentas públicas que presentan los gobiernos son una exigencia de la transición democrática en que está inmerso México, y del requerimiento de contar con un sistema de pesos y contrapesos; su finalidad es combatir y eliminar, por medio de la fiscalización, la corrupción en el ejercicio de la función pública.

\section{Figura 1}

Estratos de desarrollo de la rendición de cuentas

\begin{tabular}{|c|c|c|c|}
\hline Estratos & Información & Sanciones & Comunidad de argumentación \\
\hline Autoritario & Técnica y no accesible & Impunidad & No existe \\
\hline Democratizante & $\begin{array}{c}\text { Apertura paulatina o } \\
\text { controlada }\end{array}$ & $\begin{array}{c}\text { Aplicación } \\
\text { limitada }\end{array}$ & Incipiente \\
\hline Democrático & $\begin{array}{c}\text { Comprensible, abierta } \\
\text { y accesible }\end{array}$ & Se aplican & $\begin{array}{c}\text { Existe diversidad de vigilantes } \\
\text { independientes }\end{array}$ \\
\hline
\end{tabular}

Fuente: Pineda et al. (2007, 213).

\section{El marco legal de la revisión de cuentas públicas en Sonora}

En México, las 32 entidades federativas tienen leyes propias sobre fiscalización y cuentas públicas. Por esta razón, el orden normativo 
es distinto para cada una, y esta heterogeneidad de las leyes propicia un marco legal débil. Según González $(2009$, 9), esta divergencia entre los estados es una de las razones por la que existe una fiscalización deficiente de las cuentas públicas en México.

En Sonora, las leyes que establecen reglas sustantivas relacionadas con la fiscalización de las cuentas públicas, en orden de antigüedad, son: a) la Constitución Política del Estado de Sonora (CPES); b) la Ley de Responsabilidades de los Servidores Públicos del Estado y de los Municipios (LRSP) (1984); c) la Ley Orgánica de la Contaduría Mayor de Hacienda (1985); d) el Reglamento de la Contaduría Mayor de Hacienda del Congreso del Estado de Sonora (1986); e) la Ley del Presupuesto de Egresos, Contabilidad Gubernamental y Gasto Público Estatal (1987); f) la Ley Orgánica del Poder Legislativo (1998) y g) la Ley de Fiscalización Superior para el Estado de Sonora (LFSES) (2008a).

El anexo incluye los principales textos constitucionales sobre la cuenta pública con algunos comentarios puntuales. En la figura 2 se presentan los sujetos responsables en el servicio público, según las leyes vigentes en Sonora en 2010, y muestra los tres tipos de responsabilidades que pueden adjudicárseles, las sanciones consiguientes y las entidades encargadas de aplicar los castigos según cada caso. En la lista de los funcionarios públicos sujetos a fiscalización de las leyes estatales, el gobernador es jurídicamente intocable; sólo puede ser castigado en caso de que haya cometido "delitos graves”, a diferencia de los demás, que no tienen esta especificación. Aun así, entre los castigos posibles aplicables no se encuentra el de cárcel o privación de la libertad. Esto puede significar dos cosas: a) que los sujetos responsables en el servicio público están exceptuados de este castigo, pero no cualquier otro ciudadano y b) que se aplica en forma discrecional. El hecho de no estar explícita la pena de cárcel en los posibles castigos para los funcionarios de gobierno genera la sospecha de que la ley no se aplica a todos por igual, sino que hace excepción de personas, según se trate de ciudadanos o de servidores públicos, de camaradas o de rivales de partido.

La Constitución del estado fue reformada en 2005, a fin de ajustarse a los cambios y mejoras en la fiscalización federal, y para sustituir la Contaduría Mayor de Hacienda (CMH) por el ISAF (Boletín Oficial 


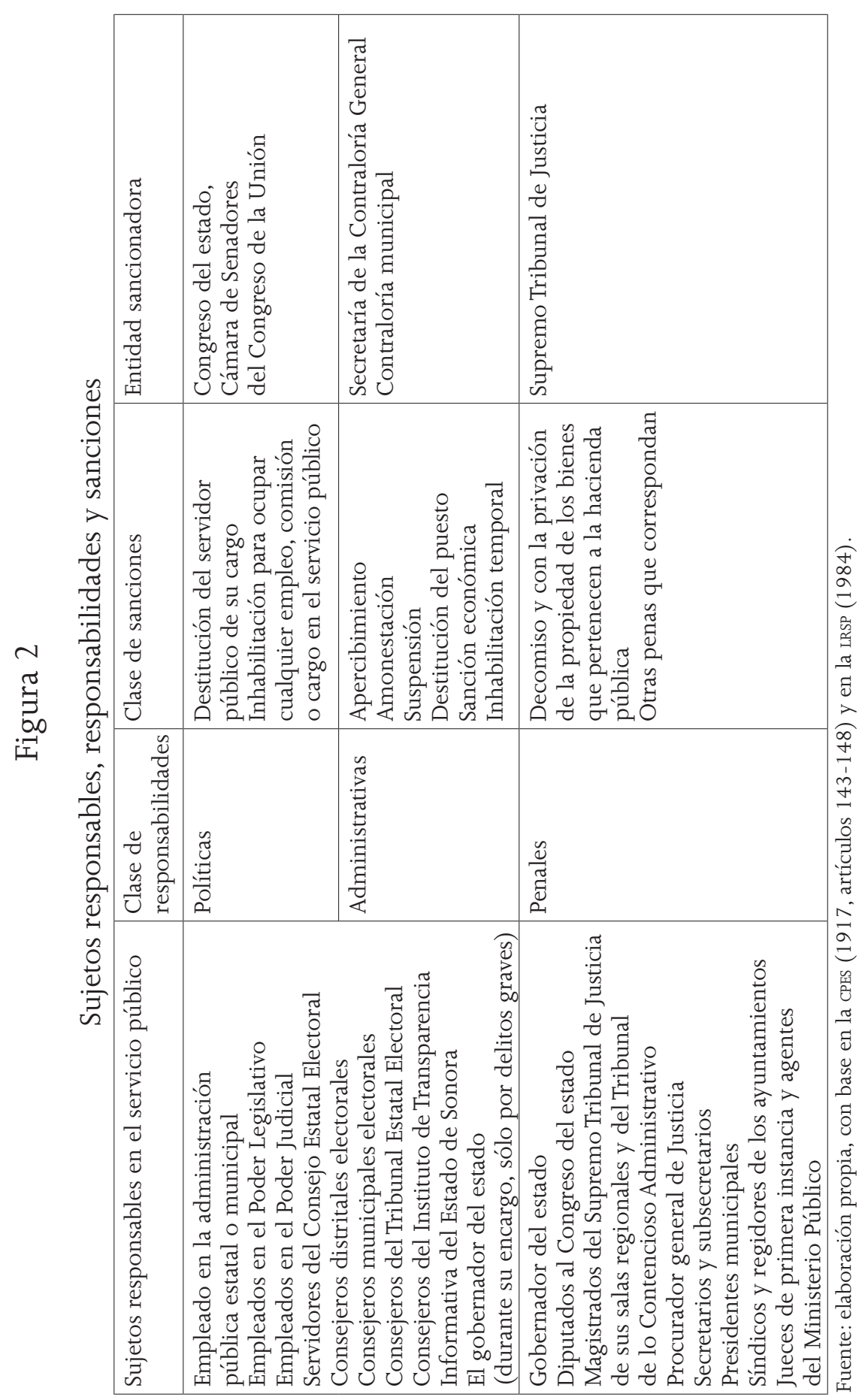


no. 3, sección 2, 11 de julio de 2005). El punto medular de esta reforma consistió en la adición del artículo 67, el cual declara la creación del nuevo órgano técnico del Congreso, sus características y atribuciones específicas. La reforma estipula además la expedición de la LFSES (2008a), que es secundaria para el nombramiento del auditor mayor y los requisitos que debe reunir, y fue promulgada tres años después. Según el informe de la Segunda Comisión de Gobernación y Puntos Constitucionales (2008b, 1) de la LVIII Legislatura, el propósito de la ufses es "dotar al Instituto de Auditoría y Fiscalización de todas las herramientas jurídicas que le permitan cumplir su cometido en beneficio de la sociedad sonorense.” Además, la LFSES especifica el proceso de selección del auditor mayor del ISAF, así como las atribuciones del órgano técnico del Congreso estatal.

Con la aprobación de esta ley, se dota al ISAF de autonomía presupuestaria, técnica y de gestión; la primera es la capacidad que tiene la entidad fiscalizadora para obtener recursos sin aprobación previa del Legislativo, y la segunda se refiere a la facultad de decidir sobre su organización interna, su funcionamiento y resoluciones, la regulación de las responsabilidades para resarcir daños y para llevar por cuenta propia el procedimiento para que el daño patrimonial a la hacienda pública sea reparado.

La LFSES de 2008 establece las atribuciones de la entidad fiscalizadora, de la Comisión de Vigilancia del Congreso del Estado de Sonora y las del auditor mayor. Esta ley muestra también cómo deben estar integradas las cuentas públicas estatal y municipal; enumera las consideraciones sobre la función de auditoría, revisión y fiscalizadora del IsAF, y explicita el objeto de su función. Por otro lado, habla sobre los derechos y las obligaciones de los sujetos de fiscalización, de los elementos que deberá contener el informe de resultados de la revisión de la cuenta pública que el ISAF deberá entregar al Congreso, la determinación de los daños y perjuicios y el fincamiento de indemnizaciones, el tipo de sanciones que puede imponer el instituto y los criterios para aplicarlas y el recurso de revisión, entendido como la impugnación de las sanciones y resoluciones del IsAF al que tienen derecho los servidores públicos o particulares ante él.

El artículo 2 vi de la LFSEs define la fiscalización como"la facultad para conocer, revisar, auditar y evaluar el uso y aplicación de los 
recursos públicos, de conformidad con las disposiciones constitucionales y legales, a cargo del Instituto”. También describe el significado de los conceptos de "pliego de observaciones", "recomendaciones" y "fiscalización superior", que se usan en el documento. Entre otros aspectos, en el artículo 3 aclara que los sujetos de fiscalización son todas las entidades que reciban, administren y ejerzan recursos públicos en los poderes Ejecutivo y Legislativo, órganos autónomos, las universidades e instituciones públicas de educación superior, los ayuntamientos y sus dependencias y cualquier persona física y moral.

La ley establece que el ISAF es el encargado de revisar anualmente las cuentas públicas mostradas por los sujetos de fiscalización y los estados financieros de la entidad y de los municipios, que deberán ser presentados en el transcurso de 45 días posteriores a la finalización del año presupuestal. La novedad de esta ley consistió en que dota al instituto de la facultad de realizar por cuenta propia el procedimiento para aplicar sanciones, con la finalidad de asegurar la reparación del daño patrimonial. Sin embargo, la ley no lo faculta para decidir quién debe de ser sancionado ni para aplicar dichas sanciones, ya que debe trasferir estos casos a la Secretaría de la Contraloría General.

La LFSES formula los mismos criterios de fiscalización para la cuenta pública estatal y la municipal, pero hace uso distinto de verbos para referirse a una u otra cuenta. Esta ley, cuando alude a las cuentas públicas agrega el verbo auditar a la par de otros que aparecen en el texto de la constitución local. En efecto, el ISAF tiene la función de revisar y fiscalizar las cuentas públicas, y la de auditar (artículo 23). Las observaciones que surjan a partir del proceso serán hechas del conocimiento de los sujetos de fiscalización para que las atiendan, inclusive antes de que concluya el informe de resultados de la misma (artículo 23, iv). En caso de no ser presentado el informe respectivo de la cuenta pública, ni los trimestrales de los estados financieros en los plazos y términos que indica la Constitución del estado, los sujetos fiscalizables serán sancionados según lo previsto por la citada ley (artículos 42 a 51) y por la LRSP.

Asimismo, el informe de resultados contiene un pliego de observaciones y las medidas para solventarlas. Las observaciones son 
agrupadas o categorizadas según sea su gravedad o materia, con la finalidad de que las medidas que se apliquen se adecuen a ellas. Las observaciones se clasifican en cuatro clases: de consistencia, preventivas, correctiva y de daño patrimonial; las tres primeras no implican daño patrimonial. Se dice que la de consistencia es de gabinete, y busca aclarar las incongruencias existentes en los informes; la segunda trata de corregir las omisiones, procedimientos u obligaciones que se hubieran encontrado en las cuentas públicas; la tercera se hace cuando se descubren situaciones de riesgo que pudieran desembocar en daños y perjuicios a la hacienda pública o dejar ventanas abiertas para actos de corrupción y las últimas, cuando se acredita daño patrimonial, se cuantifican los procedimientos legales para la restitución del daño y la aplicación de sanciones. Para cumplir con sus funciones, el ISAF puede realizar auditorías de tipo legal, financiera, presupuestal, de desempeño, técnica a la obra pública e integral (artículos 34 y 40, IX).

La LFSES contempla una serie de sanciones, que están detalladas en la ley, así como en la LRSP, para los sujetos de fiscalización que hayan incumplido con sus obligaciones. Las acciones restitutorias que realice la entidad fiscalizadora son independientes de la aplicación de sanciones administrativas y penales, que las autoridades competentes pueden imponer a los servidores públicos, y tienen por objeto recuperar el monto del daño patrimonial, estimable en dinero, causado por ellos a los gobiernos estatal y municipal y a los entes públicos.

Los sujetos de fiscalización deben presentar la indemnización de las observaciones en un plazo no mayor a 30 días hábiles, contados a partir de la fecha de recepción. Los servidores públicos expondrán además un programa de compensación, y en caso de no solventar las observaciones relacionadas con los daños a la hacienda pública en el plazo especificado, o si la documentación o argumentos esgrimidos no fueran considerados suficientes por el órgano técnico del Congreso del estado, entonces se procederá al fincamiento de responsabilidades ante la autoridad competente y será solicitada, de manera directa, la indemnización resarcitoria en beneficio del patrimonio público. Por último, el importe obtenido por las multas impuestas a causa de la violación de las disposiciones de la LFSES es 


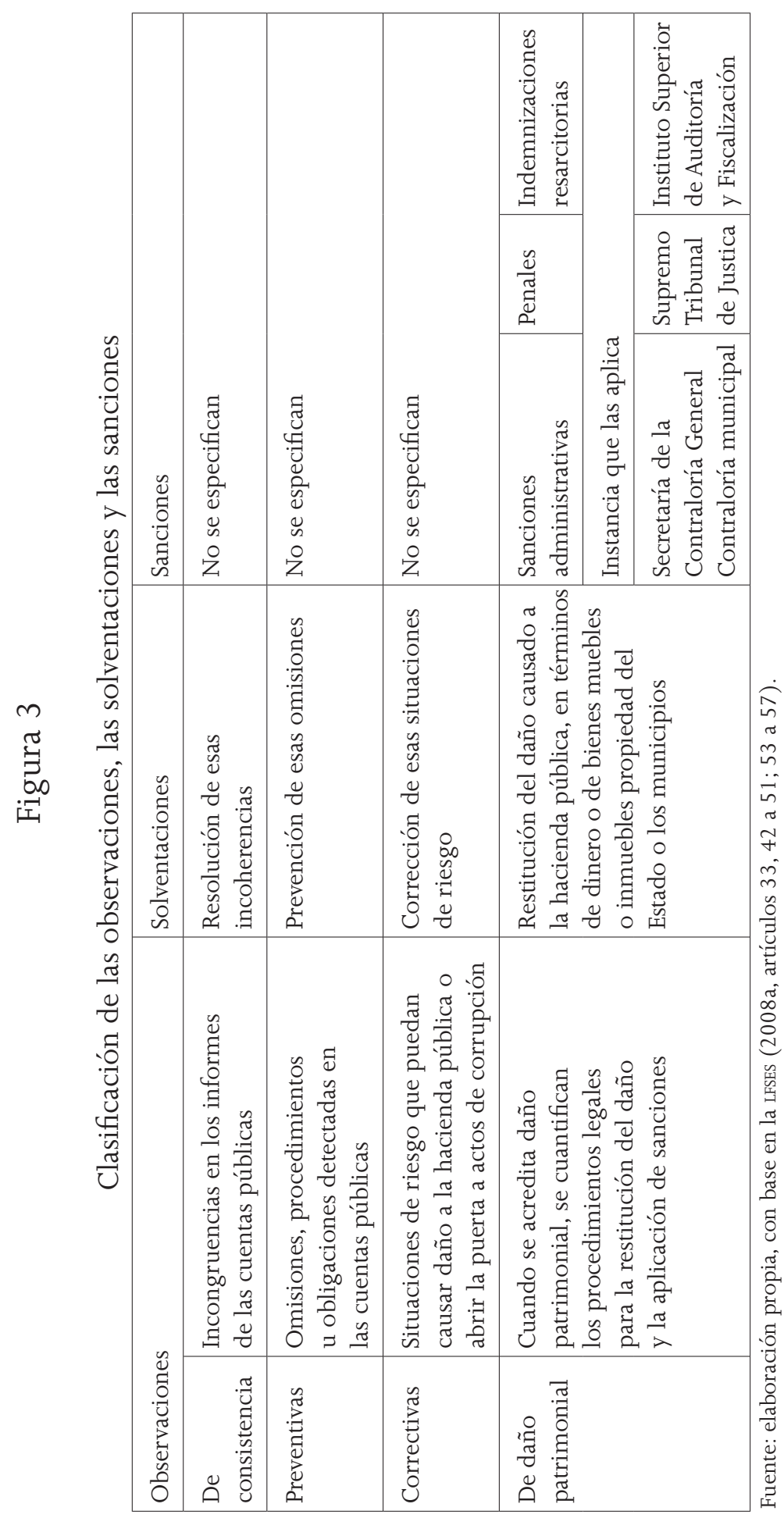


depositado en el fondo de fortalecimiento para la fiscalización superior del estado de Sonora (artícuo 57). Es importante mencionar que la LFSES subraya que la facultad del ISAF para determinar los daños cometidos al erario público y fincar directamente las indemnizaciones correspondientes prescribe en tres años, a partir de cometida la infracción (artículo 50).

En suma, el marco legal existente en Sonora sobre la fiscalización de las cuentas públicas carece de precisión en varios aspectos, y no garantiza la puesta en práctica de una rendición de cuentas que satisfaga las expectativas de la teoría. Las sanciones sobre esta materia consisten en multas, resarcimiento de daños o perjuicios a la hacienda pública, suspensión, inhabilitación y destitución del cargo público. Sin embargo, las dos últimas no reparan los daños cometidos a los bienes del estado. Asimismo, la LFSES, de 2008, faculta al ISAF, por primera vez desde su creación, para promover el fincamiento de responsabilidades ante las autoridades competentes y también de las indemnizaciones resarcitorias, en caso de que los sujetos de fiscalización hayan incurrido en acciones o conductas en detrimento del erario público. Sin embargo, el instituto no puede aplicar sanciones administrativas, las cuales son atribución exclusiva de la Secretaría de la Contraloría General. Por tanto, la Constitución estatal limita el campo de acción del ISAF.

Como lo señala Merino (2009), las leyes sobre la fiscalización y la presentación de las cuentas públicas en México están lejos de alcanzar una calidad adecuada. En las evaluaciones de la normatividad de los estados de 2004 a 2007, efectuadas por González de Aragón (2009) y Figueroa Neri (2009), la calificación de Sonora fue de 60 puntos, en una escala del 0 al 100. Aunque para 2008, con las reformas realizadas, subió a 80 .

\section{Los órganos encargados de la fiscalización}

Desde el punto de vista institucional, la encargada de la función fiscalizadora es la Comisión de Vigilancia del Congreso del Estado de Sonora y un órgano técnico, antes denominado contaduría, y que 
en fecha más reciente fue convertido en instituto. Dicha comisión ha estado conformada por entre cinco y siete diputados de las fracciones partidistas, y su función es dictaminar la revisión de las cuentas públicas del año anterior, hecha por el ISAF; funge como intermediaria, pues recibe del Congreso los estados financieros trimestrales y las cuentas públicas de la entidad y los municipios, para turnarlos al ISAF, el que a su vez los recibe, los revisa, fiscaliza y elabora el informe de resultados de la cuenta pública estatal del año anterior para la comisión, misma que lo envía al pleno del Congreso para su calificación y aprobación. Además, supervisa el programa anual de actividades que elabora el ISAF; vigila, evalúa y coordina el desempeño de sus funciones; puede solicitar que comparezca el auditor mayor, para explicar aspectos específicos; presenta ante el Congreso la propuesta de aspirantes a los cargos de auditor mayor y de auditores adjuntos y da seguimiento a las solicitudes de remoción de éstos (LFSES 2008, artículo 20, I-x). De 2004 a 2010, en los periodos correspondientes a las legislaturas LVII, LVIII y LIX, la presidencia de esta comisión fue ocupada por el PRI. Esto significa que este partido ha ejercido mayor influencia sobre los criterios que han prevalecido y las decisiones que se han tomado en ella.

\section{Figura 4}

Comisiones de vigilancia de las legislaturas LVII, LVIII y LIX

\begin{tabular}{|l|c|c|c|c|l|c|}
\hline \multirow{2}{*}{ Legislatura } & \multicolumn{3}{|c|}{ Partidos políticos representados } & $\begin{array}{c}\text { Diputado presidente/ } \\
\text { partido }\end{array}$ & Total \\
\cline { 2 - 7 } & PRI & PAN & PRD & PANAL & \multicolumn{1}{|l|}{$\begin{array}{l}\text { José Rodrigo Vélez Acosta } \\
\text { (2003-2005)/PRI } \\
\text { Alejandro Elías Serrano } \\
(2006) / \text { PRI }\end{array}$} & 5 \\
\hline LVIII (2006-2009) & 3 & 3 & 0 & 1 & $\begin{array}{l}\text { Edmundo García } \\
\text { Pavlovich/PRI }\end{array}$ & 7 \\
\hline LIX (2009-2012) & 3 & 3 & 1 & 1 & $\begin{array}{l}\text { Otto Guillermo Claussen } \\
\text { Iberri/PRI }\end{array}$ & 7 \\
\hline
\end{tabular}

Fuente: Congreso del Estado de Sonora (2005; 2009 y 2011). 
Por otra parte, hasta el 31 de diciembre de 2004, el órgano encargado de la fiscalización fue la CMH, definida por la Ley Orgánica de la Contaduría Mayor de Hacienda del Congreso del Estado de Sonora (1985) como "el órgano técnico del Congreso del Estado, por medio del cual se revisarán anualmente la cuenta pública del Estado que deberá presentar el Ejecutivo y las cuentas públicas de los municipios que deberán presentar los ayuntamientos" (artículo 2). Sin embargo, la cmH carecía de autonomía técnica, de gestión y presupuestaria, y su titular era designado por el gobernador del estado. Esto habla del control de facto del mandatario sobre la fiscalización que se realizaba. Además, los resultados de las revisiones efectuadas no se hacían públicos ni estaban a la disposición de los ciudadanos que quisieran consultarlos; al contrario, eran documentos que no circulaban y de acceso muy restringido.

El ISAF fue creado en 2005 como fruto de la reforma al artículo 67 de la Constitución local en ese año, y definido como "un órgano del Congreso del Estado dotado de autonomía presupuestaria, técnica y de gestión en el ejercicio de sus atribuciones y para decidir sobre su organización interna, funcionamiento y resoluciones, en los términos que disponga la ley. Estará encargado de la revisión y fiscalización de los estados financieros y cuentas públicas estatal y municipales" (artículo 67). El ISAF revisó las cuentas públicas de 2004 a 2010, y la CMH las de los años anteriores.

El primer auditor mayor del ISAF fue el contador público Eugenio Pablos Antillón, y su gestión inició el 1 de enero de 2005 y culminó el 31 de diciembre de 2011. En dicho año, el ISAF estaba conformado por un auditor mayor y dos adjuntos; el primero encargado de las cuentas del gobierno estatal y los otros de las municipales. El instituto contaba además con las direcciones de Asuntos Jurídicos, de Administración, de Fiscalización de Obras Públicas, de Tecnologías de Información y de Evaluación al Desempeño, y tenía 105 personas en su plantilla laboral. Hay que señalar que muchas de las auditorías que lleva a cabo se le encargan a despachos externos y, por lo tanto, las realizan auditores que no son empleados propios.

En Sonora, los resultados de la revisión de la cuenta pública se comenzaron a hacer públicos por vez primera en 2004, en la página 
de internet del Congreso del estado, luego continuaron publicándose en la página del IsAF (Pineda y Salazar 2011, 153).

\section{Proceso de revisión de la cuenta pública estatal}

En la figura 5 se describe el proceso de organización e integración de las cuentas públicas del estado y de los 72 municipios a cargo de la Secretaría de Hacienda, dependencia que elabora, entre el 1 de enero y 15 de abril, la cuenta pública del año anterior. Es decir, la de 2004 en 2005, la de 2005 en 2006, y así sucesivamente, para que el gobernador la envíe al pleno del Congreso, antes del 15 de abril; éste la recibe y la entrega a la Comisión de Vigilancia, que a su vez la remite al ISAF. Este último tiene de plazo hasta el 30 de agosto para hacer la revisión del año anterior, y entregar el informe de resultados a la mencionada comisión, que turna el informe al pleno del Congreso para que lo revise, analice y emita su dictamen de aprobación o no aprobación. El Congreso tiene hasta el 15 de septiembre para enviar las observaciones a la Secretaría de la Contraloría General, para que ésta exija que se solventen a las dependencias de gobierno, las que acuerdan con el ISAF un programa para solventar las observaciones.

En caso de que las dependencias de gobierno incumplan solventar las observaciones en los plazos señalados, el ISAF tiene la facultad sólo de fincar responsabilidades compensatorias para promoverlas ante el Congreso del estado, Secretaría de la Contraloría General, contralorías municipales y Supremo Tribunal de Justicia del Estado, y de obligar a reparar el daño causado a la hacienda pública. La Secretaría de la Contraloría General es la única instancia capaz de sancionar en lo administrativo, es decir, amonestar, inhabilitar, imponer multas económicas o suspender de su cargo a los funcionarios públicos. Los delitos del fuero común son competencia del Supremo Tribunal de Justicia del Estado.

Las conclusiones constituyen la parte más relevante del informe de resultados que emite el instituto, puesto que incluyen las observaciones de anomalías y también los comentarios de irregularidades encontradas en las cuentas públicas estudiadas, así como los 


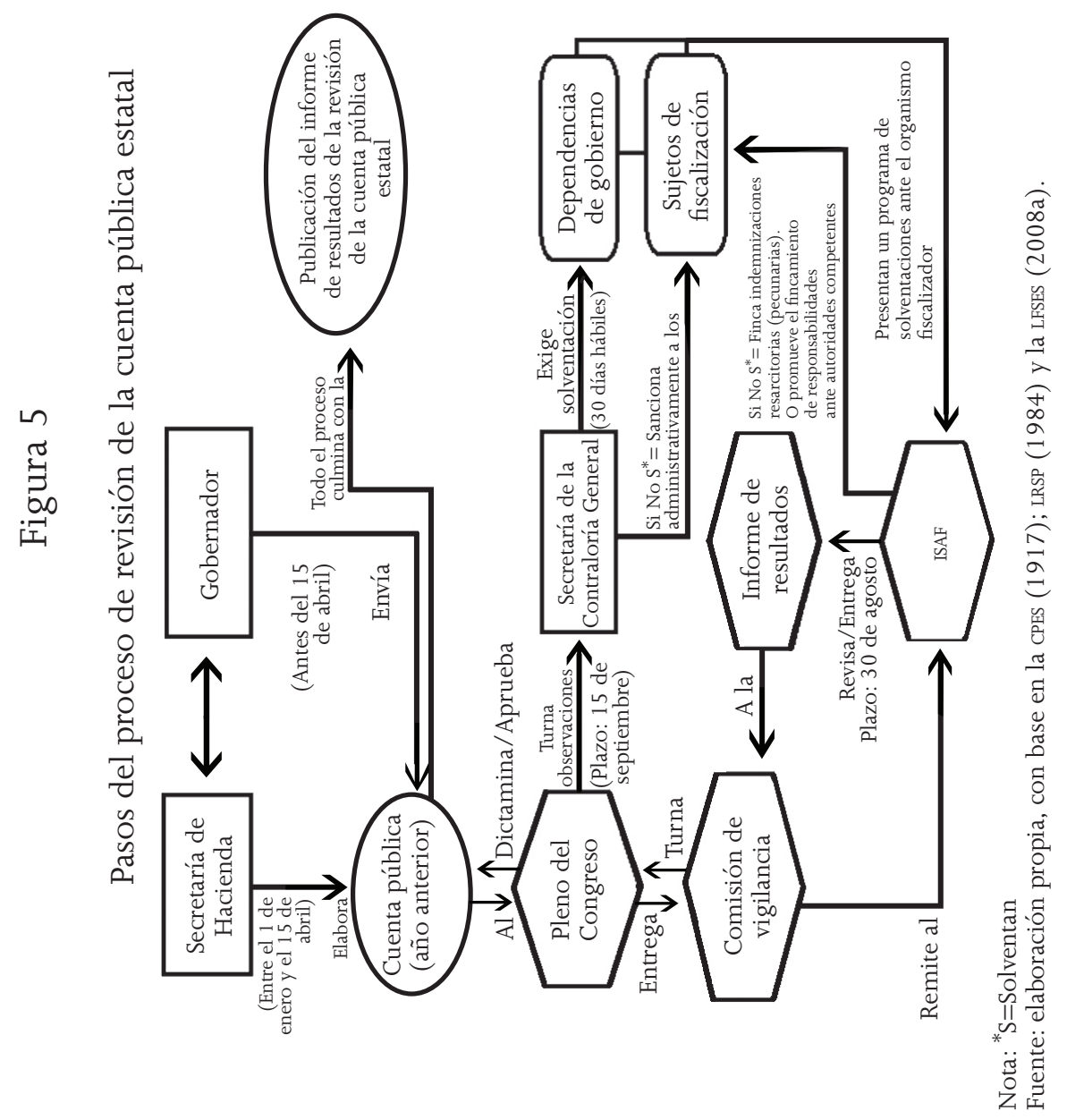


responsables. El dictamen concluye declarando como aprobatoria o no aprobatoria la cuenta pública analizada (Pineda et al. 2007, 222), y es antecedido por el siguiente párrafo, como puede verse en el informe de resultados de 2005: "La Cuenta Pública Estatal correspondiente al ejercicio 2005, presenta razonablemente en lo general la situación financiera, así como los resultados de las operaciones realizadas de conformidad con las disposiciones legales aplicables y los Principios de Contabilidad Gubernamental" (ISAF-Sonora 2006, 212).

Por otro lado, el párrafo que contiene el dictamen del instituto, sobre la cuenta pública del estado, queda formulado según estos términos: "Por lo expuesto anteriormente y considerando la facultad exclusiva del H. Congreso del Estado en la calificación de las cuentas públicas, el Instituto Superior de Auditoría y Fiscalización propone como Aprobatorio el resultado de la revisión y fiscalización de la Cuenta de la Hacienda Pública Estatal, por el ejercicio 2005” (Ibid.).

\section{La revisión de la cuenta pública en cinco dependencias del gobierno estatal}

A fin de observar cómo se lleva a cabo el proceso concreto de fiscalización de la cuenta pública del Gobierno de Sonora, en este apartado se revisan las observaciones, solventaciones y procedimientos de sanción realizados en las cinco dependencias estudiadas, de 2004 a 2010, que son: la Oficina del Ejecutivo, las secretarías de Gobierno, de la Contraloría General, de Infraestructura y Desarrollo Urbano (SIDUR, antes SIUE) y la de Educación y Cultura (SEC). Los criterios para seleccionarlas fueron dos: primero, su importancia o relevancia política, y según éste se eligieron las tres primeras, que son las que concentran mayor poder y control político y administrativo. El segundo fue la importancia presupuestal, según el cual se seleccionó a la SEC y la SIDUR, por ser las que concentran la mayor parte del presupuesto estatal, además porque la última contrata las principales obras públicas que realiza el gobierno del estado.

Los informes de resultados de la revisión de cuenta pública estatal, hasta la elaboración de este artículo, se encuentran publicados en la 
página electrónica del ISAF.Y aunque contienen mucha información, para este estudio se revisaron las observaciones que se hacen a cada dependencia de gobierno en relación con el ejercicio presupuestal, también las ya solventadas y las que quedan pendientes.

\section{Las observaciones}

Las observaciones que contienen los informes de resultados de la revisión de las cuentas públicas se clasifican en las categorías siguientes: incumplimiento de metas (IM), irregularidades en la asignación de contratos (IAC), irregularidades en la obra pública (IOP), gastos no comprobados (GNC), gastos no autorizados (GNA) e incumplimiento de deberes institucionales (IDI). Como puede verse, las dos primeras se refieren a la eficiencia de cada dependencia; la de IAC tiene que ver con la discrecionalidad en las contrataciones externas; la de GNC y la de GNA pudieran ser atribuidas a actos de corrupción. Por último, la de IDI se refiere a la omisión de procedimientos en los plazos y de la presentación de los informes trimestrales del ejercicio fiscal correspondiente. Para ver el impacto financiero y presupuestal que tienen las observaciones sobre el presupuesto que ejerce cada dependencia, se separan las que no tienen un monto presupuestal de las que sí lo tienen; estas últimas pueden cuantificarse y compararse con el presupuesto ejercido por cada dependencia, y ayudan a observar la repercusión que tienen sobre dicho monto (Pineda y Salazar 2008).

En el periodo estudiado (2004-2010), el ejecutivo del estado no tuvo observaciones; la Secretaría de la Contraloría General presentó 26, (8 por ciento del total), generadas para las cinco dependencias, pero las solventó todas antes de la publicación del informe de resultados; la Secretaría de Gobierno obtuvo 53 (15); la SEC 75, (22) y la SIDUR 189, (55 por ciento del total) de las correspondientes al periodo mencionado. Se desprende entonces que la siDuR fue la que tuvo más, y la segunda fue la SEC.

En cuanto a la evolución que ha tenido el número de observaciones a lo largo del periodo, se observa que estas cinco dependencias recibieron sólo 3 en 2004; 4 en 2005; 50 en 2006; 59 en 2007; 64 
en 2008; 66 en 2009 y 97 en 2010. Como se aprecia, han aumentado de forma gradual.

La categoría de observaciones más presente en los informes de resultados es la que corresponde a la de IOP, con 84, que equivale a 60 por ciento del total de 140 susceptibles de clasificación, pues sólo fue posible clasificar las no solventadas, que aparecen en los informes de resultados. ${ }^{1}$ La segunda categoría en importancia en cuanto al número de observaciones que incorporó fue la de GNA, con 17 unidades y 12 por ciento. En tercer lugar está la de GNC, con 16 y 11 por ciento del total de las observaciones no solventadas. En cuarto lugar, la de IDI, con 13 unidades y 9 por ciento del total. En el quinto sitio, la de IM, con 8 observaciones pendientes y 6 por ciento del total. En último lugar está la categoría de IAC, con dos observaciones y 1 por ciento del total de las observaciones pendientes.

\section{Figura 6}

Observaciones a dependencias hechas en los informes de resultados (2004-2010)

\begin{tabular}{|l|r|r|r|r|r|r|r|r|}
\hline Dependencia & IM & IAC & IOP & GNC & GNA & IDI & Total & $\%$ \\
\hline Ejecutivo del estado & 0 & 0 & 0 & 0 & 0 & 0 & 0 & 0 \\
\hline Secretaría de la Contraloría General & 0 & 0 & 0 & 0 & 0 & 0 & 0 & 0 \\
\hline Secretaría de Gobierno & 1 & 0 & 1 & 1 & 4 & 0 & 7 & 5 \\
\hline Secretaría de Infraestructura y Desarrollo Urbano & 4 & 2 & 76 & 7 & 6 & 10 & 105 & 75 \\
\hline Secretaría de Educación y Cultura & 3 & 0 & 7 & 8 & 7 & 3 & 28 & 20 \\
\hline Totales & 8 & 2 & 84 & 16 & 17 & 13 & 140 & 100 \\
\hline Porcentajes & 6 & 1 & 60 & 11 & 12 & 9 & 100 & \\
\hline
\end{tabular}

Claves: IM: incumplimiento de metas; IAC: irregularidades en la asignación de contratos; IOP: irregularidades en la obra pública; GNC: gastos no comprobados; GNA: gastos no autorizados.

Fuente: elaboración propia, a partir de los informes de resultados (IsAF-Sonora 20052010).

${ }^{1}$ Las observaciones no solventadas son las únicas categorizables, porque vienen en los informes de resultados que emite el ISAF. Las solventadas, en tanto que ya fueron resueltas, no aparecen en dichos informes $y$, por lo tanto, no pudieron ser categorizadas. 
De lo anterior se desprende que las categorías IOP, GNA y GNC, por sus impactos en el presupuesto, son las que presentan mayor oportunidad para la malversación de fondos públicos, y tienen más presencia en los siete informes de resultados escrutados, y se concentran en la SIDUR y en la SEC.

Las observaciones de la categoría IOP predominan en la SIDUR, con 76, equivalentes a 90 por ciento del total en las cinco dependencias durante el periodo. Las de GNC y GNA son más numerosas en la SEC, con ocho observaciones de GNC, que constituyeron 50 por ciento del total de este tipo, obtenidas en las cinco dependencias en el periodo, y 7 de GNA, que representaron 41 por ciento. Las observaciones de tipo daño patrimonial no aparecen en los informes de resultados, y corresponderían a trasferencias bancarias o gastos efectuados no conceptuados, ni reportados al ISAF.

Hay que señalar que de 2004 a 2010, de un total de 140 observaciones que quedaron pendientes de saldar, se registraron 43 con impacto financiero, que sumó 359683019 pesos. Las cuantificadas

\section{Figura 7}

Tipología y porcentaje de las observaciones con impacto financiero

\begin{tabular}{|l|r|r|r|r|r|r|r|r|r|r|}
\hline \multicolumn{7}{|c|}{$2004-2010$} \\
\hline Dependencias & OP & OM & GNA & $\%$ & GNC & $\%$ & IOP & $\%$ & $\%$ & Monto (pesos) \\
\hline $\begin{array}{l}\text { Seccutivo del estado } \\
\text { General }\end{array}$ & 0 & 0 & 0 & 0 & 0 & 0 & 0 & 0 & 0 & \\
\hline Secretaría de Go la Contraloría & 0 & 0 & 0 & 0 & 0 & 0 & 0 & 0 & 0 & \\
\hline $\begin{array}{l}\text { Secretaría de Infraestructura } \\
\text { y Desarrollo Urbano }\end{array}$ & 105 & 26 & 0 & 0 & 4 & 9 & 21 & 49 & 58 & 74934853 \\
\hline $\begin{array}{l}\text { Secretaría de Educación y } \\
\text { Cultura }\end{array}$ & 28 & 16 & 10 & 23 & 6 & 14 & 1 & 2 & 40 & 282677049 \\
\hline Totales & 140 & 43 & 10 & 23 & 11 & 26 & 22 & 51 & 100 & 359683019 \\
\hline
\end{tabular}

Claves: OP: observaciones pendientes; OM: observaciones con monto; GNA: gastos no autorizados; GNC: gastos no comprobados; IOP: irregularidades en la obra pública.

Fuente: elaboración propia, a partir de los informes de resultados (ISAF-Sonora 20052010). 
equivalen a 30.71 por ciento del total de las observaciones pendientes.

Es interesante destacar que la Oficina del Ejecutivo del estado no recibió observaciones en el periodo analizado. En situación similar estuvo la Secretaría de la Contraloría General, que durante 2004 y 2005 tampoco las obtuvo. Las razones de la ausencia de observaciones en estas dos dependencias, caracterizadas una por ser la que concentra más poder y la otra por ser la más afín a las tareas del ISAF, es motivo de interpretación y de debate, y pueden aducirse a que en efecto son muy cuidadosas en sus procedimientos; o bien, que se trata de una variación en los criterios de auditoría y fiscalización empleados.

\section{La solventación}

Como se mencionó, después de la publicación de las observaciones de cada dependencia, la Secretaría de la Contraloría General se encarga de dar seguimiento a la solventación, es decir a la justificación y resolución de cada una de ellas. El ISAF, por su parte, informa sobre las observaciones solventadas y las pendientes en los informes de resultado de los años subsecuentes.

Al revisar la evolución del número de solventaciones durante el periodo, se advierte un incremento evidente de 2004 a 2007, pero un decremento de 2007 a 2009, y un repunte de 2009 a 2010. Es decir, que las cinco dependencias solventaron menos sus observaciones en los ejercicios fiscales de 2004 y 2005 y más en los de 2006 y 2007; de 2008 a 2009 disminuyeron y repuntaron de 2009 a 2010. El número de observaciones solventadas no tendió a aumentar progresivamente como en el caso de las observaciones (véase figura 8).

Además, se aprecian diferencias en las dependencias; la Secretaría de la Contraloría General fue la que más solventó las observaciones que recibió durante la fiscalización de sus cuentas, pues fue capaz de solventar las 26 recibidas durante el periodo. La segunda fue la Secretaría de Gobierno, que solventó 46 (86.79 por ciento) de las 53; le siguió la SEC con 47 (63 por ciento) de las 75, y en último lugar se ubica la siDUR, que solventó 84 (44 por ciento) de 189. La Oficina 


\section{Figura 8}

Observaciones solventadas por las cinco dependencias del gobierno estatal de 2004 a 2010

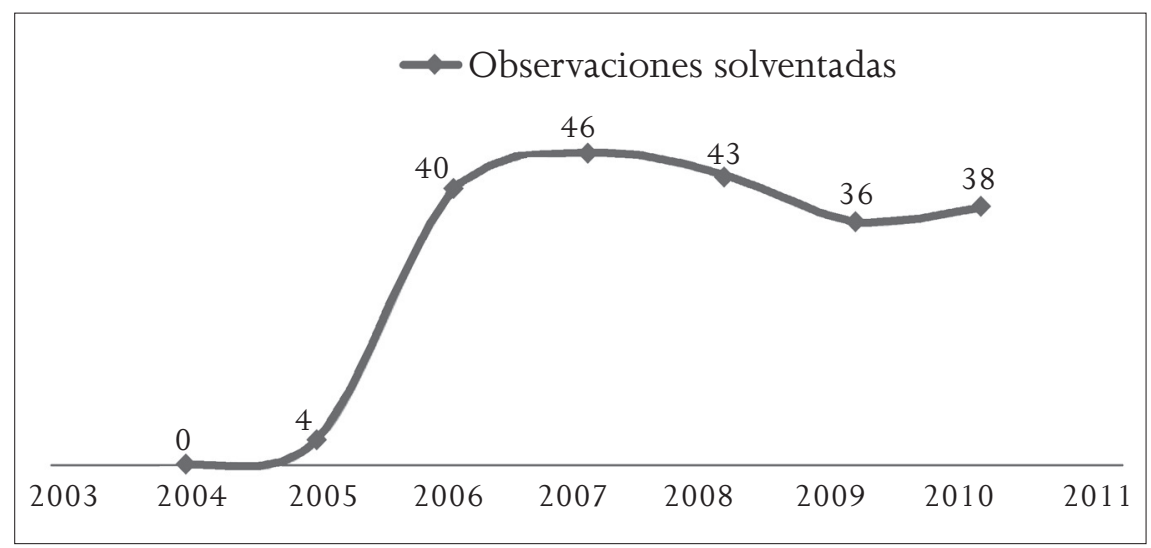

Fuente: elaboración propia, a partir de los informes de resultados (ISAF-Sonora 20052010).

del Ejecutivo no se incluye ya que, según se mencionó, al no recibir observaciones, tampoco tenía que solventarlas (véase figura 9).

Las sanciones

En lo que se refiere a los procedimientos de sanción a las observaciones no solventadas, el ISAF, en sus informes de resultados, no publica datos sobre los funcionarios sancionados o castigados por malversación de fondos o por incurrir en actos ilícitos en su desempeño, puesto que no tiene facultades para sancionar.

Como se vio, la Secretaría de la Contraloría General es la encargada de llevar adelante los procedimientos de sanción; sube a su página oficial listas de funcionarios públicos estatales que han sido amonestados, suspendidos, inhabilitados o destituidos del puesto, pero no se especifican los motivos o causas de dichas sanciones, ni se indica el puesto que desempeñaban. Ya que hay muchos otros 


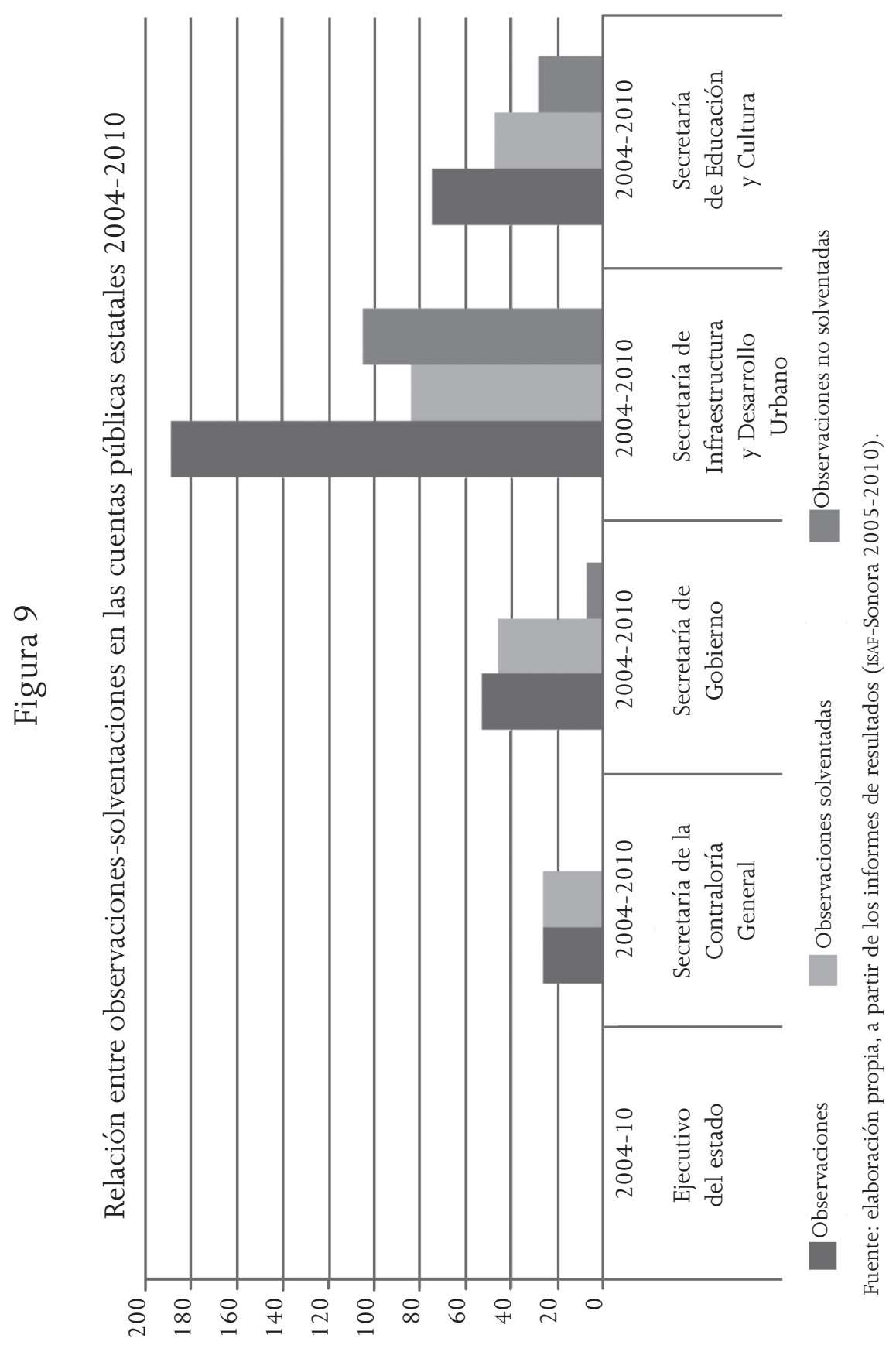


motivos, diferentes a los de la fiscalización del gasto público, por los que pueden ser sancionados, en estricto sentido, no hay información que permita vincular a dichos servidores con la falta de solventación de las observaciones; sólo se conoce el castigo, pero no la falta cometida.

La lista de funcionarios estatales sancionados, publicada por la Secretaría de la Contraloría General en su portal, abarca del 29 de enero de 2001 al 23 de septiembre de 2009, y ocupa un aproximado de 30 cuartillas; y aún no está disponible la lista de los sancionados en 2010 y 2011.

La figura 10 proporciona la relación de los sancionados estatales de 2004 a 2009, de las cinco dependencias de gobierno analizadas, y el tipo de sanciones más frecuentes o las que más se aplicaron, que fueron las amonestaciones, le siguieron las inhabilitaciones, luego los apercibimientos, las suspensiones y las destituciones del puesto. En ese lapso hubo 59 funcionarios amonestados, 36 inhabilitados, 26 apercibidos, 23 suspendidos y 11 destituidos del puesto, para alcanzar los 155 . Esto significa que sólo 20 por ciento del total de empleados fue sancionado (Secretaría de la Contraloría General 2011). Las inhabilitaciones varían, desde 1 mes hasta 10 años; son las sanciones más fuertes. Las suspensiones, en cambio, de un día a 12 meses. Las destituciones del puesto son definitivas. Las amonestaciones son meras llamadas de atención, escritas u orales, a causa de infracciones leves en las que puede incurrir un funcionario. El apercibimiento consiste en la comparecencia de un servidor público ante la autoridad respectiva.

En la figura 11 se aprecia la tendencia del número de funcionarios sancionados en las cinco dependencias del gobierno estatal, de 2004 a 2009, correspondiente al sexenio del gobernador Eduardo Bours, y no incluye el cambio de administración. Fue en 2004, al inicio de dicho sexenio, cuando las cinco exhibieron el mayor número de funcionarios sancionados (28), lo cual coincide con la menor cantidad de observaciones que se generaron en ese mismo año. En 2005 y 2006 fueron 22 y 19 respectivamente, hubo un ligero repunte en 2007, a la mitad del sexenio, cuando subió a 28, y continuó disminuyendo en 2008 a 18, y a 14 en 2009. 


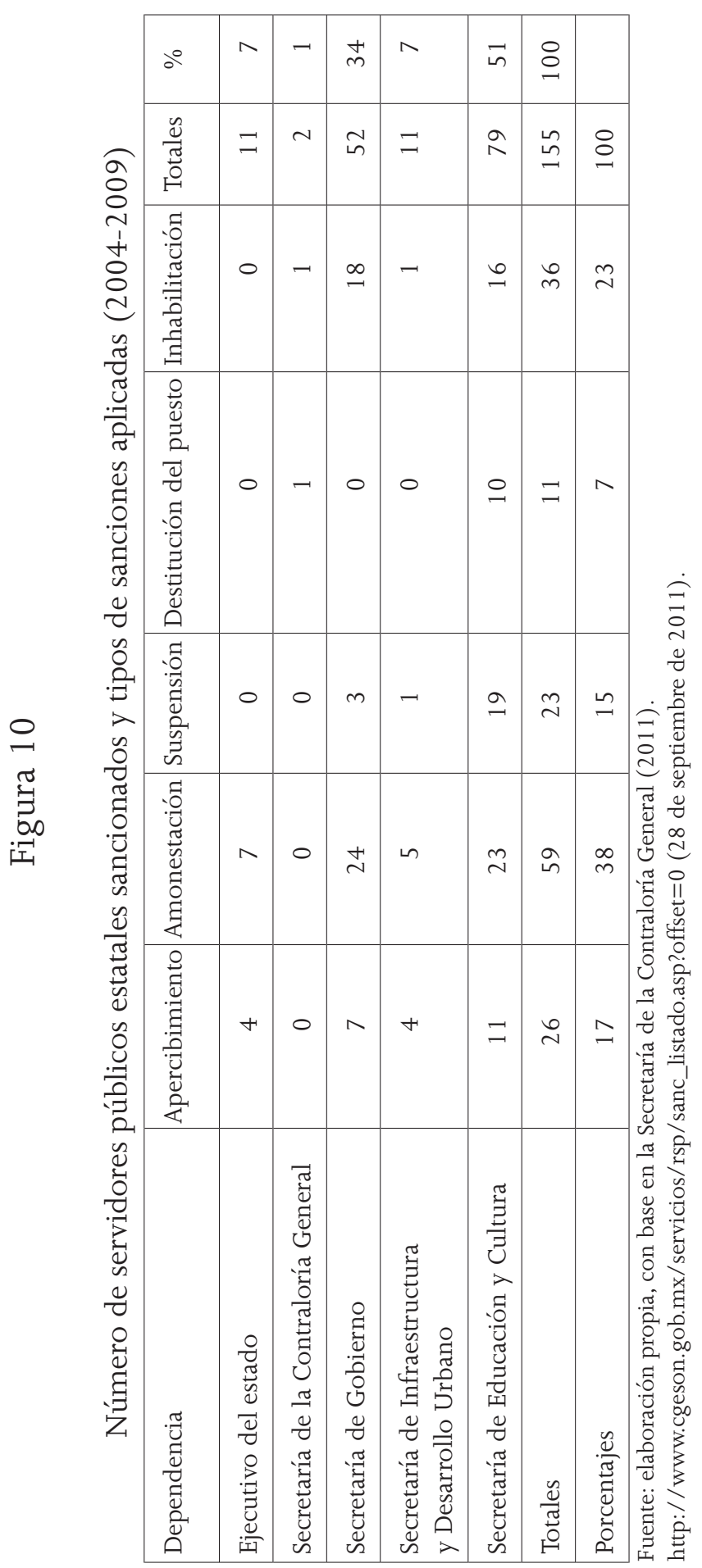


De este modo, en el sexenio 2003-2009, el número de funcionarios sancionados bajó de 52 a 14. Se requeriría un estudio comparativo para verificar si este tipo de evolución corresponde a un patrón sexenal, o más análisis de datos para ver si responde a un ciclo de aprendizaje o a una reducción efectiva de las conductas sancionables. Aquí es importante destacar que existe una relación inversa entre la cantidad de observaciones realizadas en las revisiones de las cuentas públicas y el número anual de funcionarios sancionados.

\section{Figura 11}

Tendencia del número de funcionarios sancionados 2004-2009

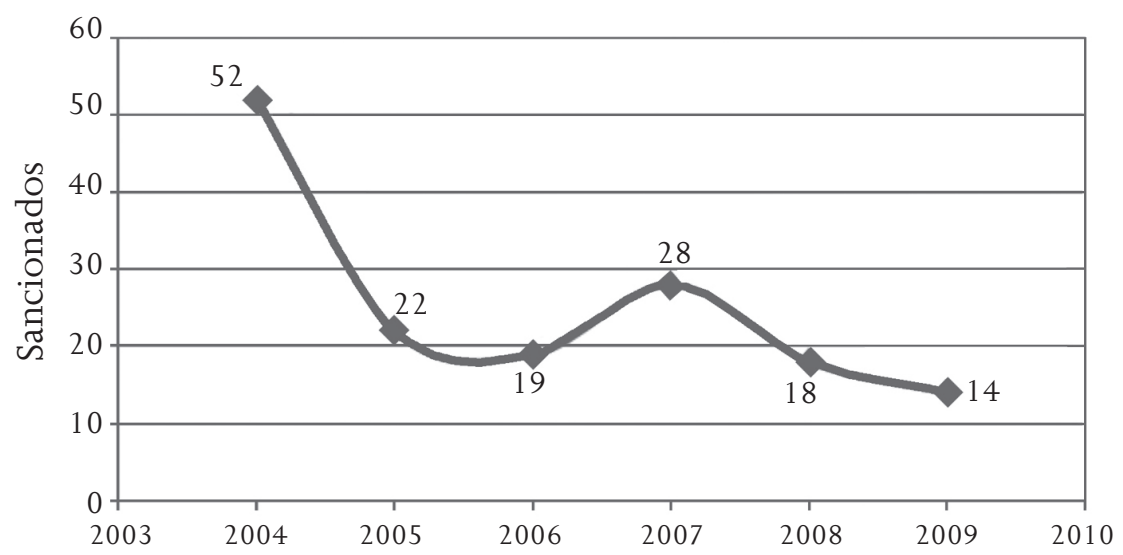

Fuente: elaboración propia, con base en la Secretaría de la Contraloría General (2011).

En conclusión, la información sobre las observaciones, su solución y los procedimientos de sanción resulta ambigua y confusa en varios sentidos. Las observaciones más frecuentes son las de los GNC y las de IOP, y el número de ellas durante el periodo en las cinco dependencias mostró un incremento, también aumentaron las pendientes. Sin embargo, las sanciones aplicadas disminuyeron. Se advierte una relación inversamente proporcional entre el número de observaciones y las pendientes de solventar con el de funcionarios 
sancionados pues, a medida que ellos disminuyen, aumentan tanto las observaciones hechas como las pendientes de solventar, mismas que no es posible vincular con las sanciones. Por ello, se desconoce si se desprendieron sanciones de los siete informes de resultados de las cuentas públicas estatales de 2004 a 2010 . En cambio, quedaron observaciones pendientes de solventar de cuentas públicas pasadas y que, paradójicamente, de forma reiterada siguen apareciendo en los siguientes informes. En teoría, los sujetos responsables de solventarlas deberían ser sancionados.

\section{Reflexiones finales}

La pregunta que se planteó al inicio de este trabajo es qué tan efectiva es la función fiscalizadora que realiza el ISAF en la tarea de combatir la corrupción, entendida como la malversación de fondos públicos.

Una vez revisados el marco legal y los informes de resultados de la revisión de la cuenta pública de 2004 a 2010, referente a cinco dependencias de la administración estatal, se concluye que el proceso de fiscalización de las cuentas públicas en Sonora es débil, debido al laxo marco normativo existente, al sistema institucional que no permite que el ISAF aplique sanciones administrativas y a la falta de sanciones para los funcionarios públicos que no solventan sus observaciones en los tiempos establecidos. Por lo tanto, la fiscalización que se lleva a cabo en Sonora, si bien inhibe y desalienta la malversación de fondos y la corrupción en los mandos medios e inferiores, no evita la corrupción y deja espacios a la discrecionalidad sobre todo de alto nivel. En este proceso, el ejecutivo no es fiscalizado, sino que él decide, a fin de cuentas, a quién y cómo se sanciona.

El marco legal sobre la fiscalización y la revisión de las cuentas públicas en Sonora, si bien mostró avances considerables con la expedición de la nueva ley en 2008, no fortalece lo suficiente al ISAF como para que pueda aplicar, como órgano autónomo e independiente, las sanciones que se desprendan de la revisión y falta de solución de las mismas. En la actualidad, la encargada de decidir y sancionar es la Secretaría de la Contraloría General, una dependencia del Poder Ejecutivo; no es el Legislativo el que fiscaliza al Ejecutivo. 
Con base en el marco legal revisado, existe un supuesto implícito de que no hay una separación real entre los poderes Ejecutivo y Legislativo, y de que el primero y el secretario de la Contraloría no cometen faltas en el ejercicio del gasto, ni están sujetos a la fiscalización de la misma manera que los demás funcionarios.

La ausencia de proporción entre delitos (que pueden ser millonarios) y sanciones (que sólo remueven del cargo pero no recuperan lo perdido), la ausencia de claridad y transparencia en la aplicación de éstas, la imprecisión de las leyes y la ambigüedad de los procedimientos establecidos por el marco legal generan procesos prolijos y rigurosos en la auditoría y etapas iniciales de la fiscalización, pero débiles y arbitrarios en la final, la de aplicación de sanciones. Este tipo de procedimientos, aunque desalienta la malversación de fondos en los ámbitos burocráticos medios y bajos, a fin de cuentas allana y deja libre el terreno a las prácticas de corrupción de alto nivel dentro de la administración pública gubernamental.

En este sentido, es muy sintomática la inexistencia de observaciones y, por ende, de sanciones a la Oficina del Ejecutivo. Este comportamiento hace pensar que su gasto en estos años y durante dos periodos de gobierno ha sido escrupuloso en el cumplimiento de los procedimientos contables y presupuestales, o que no se le han aplicado los mismos criterios de auditoría y fiscalización que al resto de las dependencias. Por ello, en el arreglo institucional se percibe que no se apega al principio de pesos y contrapesos de las democracias modernas, sino que hay un supuesto implícito de que el ejecutivo y el secretario de la Contraloría no pueden ser sancionados, sino que son parte central y simbiótica del proceso de fiscalización de la administración dependiente del Ejecutivo. De otra manera no se explica que la aplicación de sanciones por faltas derivadas de la revisión de la cuenta pública, realizada por un órgano del Poder Legislativo, regrese y se encargue al mismo Ejecutivo, es decir, al sujeto fiscalizado. Es como si el juez le encargara a un sujeto, acusado por un delito en una averiguación previa, que él mismo solventara su falta y aplicara la sanción.

Las observaciones, las solventaciones y los procedimientos de sanción en las cinco dependencias del gobierno estatal estudiadas en este trabajo constituyen un mecanismo ambiguo, en el que se 
perciben lagunas y oportunidades para la malversación de fondos públicos en etapas o áreas clave del proceso de fiscalización. El número de observaciones generadas de 2004 a 2010 en dichas dependencias mostró un incremento, lo mismo que las que quedaron pendientes de solventar. Sin embargo, no se localizó información concreta sobre el número de sanciones o funcionarios sancionados, que se desprendieron de estos procesos de fiscalización. Por el contrario, la información obtenida muestra que hubo una disminución de los servidores sancionados.

Es necesario fortalecer el proceso legal de la fiscalización de las cuentas públicas en Sonora, mediante reformas a la constitución local y a la ley secundaria, que hagan efectiva la aplicación de sanciones, y que precisen con claridad las causales de éstas y el tipo de castigo que corresponde. Para ello, se hace necesario dotar al ISAF de más atribuciones, en especial las relacionadas con la aplicación de sanciones administrativas, y no limitarse sólo al resarcimiento del daño patrimonial. Más aún, a fin de avanzar hacia una fiscalización más efectiva, hace falta mejorar las reglas y los procesos e impulsar y establecer una diversidad de actores fiscalizadores, sobre todo de la sociedad civil (medios de comunicación, entidades académicas, asociaciones cívicas, grupos de ciudadanos beneficiarios o afectados), que realicen de manera regular, periódica y sistemática la revisión y fiscalización del gasto y la gestión pública del gobierno del estado. Esto demanda, por lo tanto, un avance no sólo en el gobierno sino principalmente en la cultura y el empoderamiento de los ciudadanos.

Recibido en febrero de 2012 Aceptado en abril de 2012

\section{Bibliografía}

Congreso de la Unión. 2009. Ley de Fiscalización y Rendición de Cuentas de la Federación. http://www.diputados.gob.mx/Leyes Biblio/pdf/LFrCF.pdf (11 de junio de 2011). 
2008. Ley General de Contabilidad Gubernamental. http: //www.diputados.gob.mx/LeyesBiblio/pdf/LGCG.pdf (11 de junio de 2011).

. 2000. Ley de Fiscalización Superior de la Federación. http://legal.terra.com.mx/legislacionfed/nivel1 .asp?idM=3\&rl $=20000 \& \mathrm{rf}=29999 \& \mathrm{idL}=20059$ (15 de marzo de 2011).

Congreso del Estado de Sonora. 2011. Historia del H. Congreso del Estado de Sonora. http://www.congresoson.gob.mx/historia. php (12 de julio de 2011).

. 2009. Dictámenes09/Acuerdo 302. http://www.congresoson.gob.mx/InfoPublica/LVII/Dictamenes09/ACUERDOs302.pdf (1 de enero de 2011).

2008a. Ley de Fiscalización Superior para el Estado de Sonora. http://www.congresoson.gob.mx (31 de marzo de 2011).

. 2008b. Segunda Comisión de Gobernación y Puntos Constitucionales. Hermosillo: sin editorial.

. 2005. Dictámenes05/Acuerdo 131. http://www.congresoson.gob.mx/InfoPublica/Dictamenes05/ACUERDO_131.pdf (1 de enero de 2011).

. 1998. Ley Orgánica del Poder Legislativo. http://www. congresoson.gob.mx/Leyes_Archivos/doc_78.pdf (31 de marzo de 2011).

. 1987. Ley de Presupuesto de Egresos, Contabilidad Gubernamental y Gasto Público Estatal. http://transparencia.esonora.gob.mx/NR/rdonlyres/8AA94EFB-E408-49A6- BC80-

1986. Reglamento de la Contaduría Mayor de Hacienda del Congreso del Estado de Sonora. http://www.congresoson. gob.mx/Leyes_Archivos/doc_19.pdf (31 de marzo de 2011). 
1985. Ley Orgánica de la Contaduría Mayor de Hacienda. http://www.cgeson.gob.mx/cpcem/publicaciones/LeyOrganicaContaduriaMayor.pdf (31 de marzo de 2011).

. 1984. Ley de Responsabilidades de los Servidores Públicos del Estado y de los Municipios. http://www.congresoson. gob.mx/Leyes_Archivos/doc_54.pdf (31 de marzo de 2011).

1917. Constitución Política del Estado de Sonora. http:// www.congresoson.gob.mx/Leyes_Archivos/doc_7.pdf (31 de marzo de 2011).

Del Castillo, Arturo. 2003. Medición de la corrupción: un indicador de la rendición de cuentas. México: Auditoría Superior de la Federación (ASF)/ Editorial Color.

Dunn, William N. 1994. Public Policy Analysis. An Introduction. Nueva Jersey: Prentice-Hall.

Figueroa Neri, Aimée (directora). 2009. Buenas, malas o raras. Las leyes mexicanas de fiscalización superior (2000-2009). México: ASF/Cámara de Diputados.

González de Aragón, Arturo. 2009. Introducción. En Buenas, malas 0 raras. Las leyes mexicanas de fiscalización superior (2000-2009), dirigida por Aimée Figueroa Neri, 9-10. México: ASF/Cámara de Diputados.

ISAF-Sonora. 2011. Informe de resultados de la revisión de la cuenta de la hacienda pública estatal 2010. http://www.isaf.gob.mx (15 de septiembre de 2011).

.2010. Informe de resultados de la revisión de la cuenta de la hacienda pública estatal 2009. http://www.isaf.gob.mx (24 de septiembre de 2010).

2009a. Informe de resultados de la revisión de la cuenta de la hacienda pública estatal 2008. http://www.isaf.gob.mx (24 de septiembre de 2010). .2008. Informe de resultados de la revisión de la cuenta de 
la hacienda pública estatal 2007. http://www.isaf.gob.mx (24 de septiembre de 2010).

. 2007. Informe de resultados de la revisión de la cuenta de la hacienda pública estatal 2006. http://www.isaf.gob.mx (24 de septiembre de 2010).

2006. Informe de resultados de la revisión de la cuenta de la hacienda pública estatal 2005. http://www.isaf.gob.mx (24 de septiembre de 2010).

2005. Informe de resultados de la revisión de la cuenta de la hacienda pública estatal 2004. http://www.isaf.gob.mx (24 de septiembre de 2010).

Jiménez Flores, Jaime R. 2008. La fiscalización superior y la rendición de cuentas en la coordinación fiscal en México. En Séptimo certamen nacional de ensayo sobre fiscalización superior y rendición de cuentas, de la ASF, 109-143. México: Helvética Impresos.

March, James G., y Johan P. Olsen. 1995. Democratic Governance. Nueva York: The Free Press.

Merino Huerta, Mauricio. 2011. El gasto oculto de los estados. Nexos (406): 47-48.

2009. Informe sobre la calidad de la información en las cuentas públicas en México. En La estructura de la rendición de cuentas en México, coordinado por ídem., Sergio López Ayllón y Guillermo Cejudo, 235-286. México: Universidad Nacional Autónoma de México (unAM), Centro de Investigación y Docencia Económicas.

Muñoz Amato, Pedro. 1978. Introducción a la administración pública I. México: Fondo de Cultura Económica.

O'Donnell, Guillermo. 1997. Rendición de cuentas horizontal y nuevas poliarquías. Nueva Sociedad (152): 143-167. 
Olvera, Alberto J., y Ernesto Isunza Vera. 2004. Rendición de cuentas: los fundamentos teóricos de una práctica de la ciudadanía. En Participación ciudadana y políticas sociales en el ámbito local, 335-357. México: UnAm/Instituto Nacional de Desarrollo Social.

Pineda Pablos, Nicolás y Alejandro Salazar Adams. 2011. La fiscalización sin dientes en el Gobierno del Estado de Sonora 2004 y 2005. Frontera Norte XXIII (46): 151-175.

2008. Gruñe pero no muerde. La fiscalización de los recursos públicos en el estado de Sonora. En Proyecto La rendición de cuentas gubernamental en México: evaluación de la fiscalización superior en los estados, de Alejandra Ríos Cázares, 1-45. La Jolla: Universidad de California en San Diego, Centro de Estudios México-Estados Unidos.

, Gabriela García Figueroa y Eliseo Rodríguez Camou. 2007. Democratización y rendición de cuentas. El caso de la revisión de las cuentas públicas municipales en Sonora. Gestión y Política Pública XVI (1): 203-236.

Rubio, Luis. 2011. De la falsa monarquía al feudalismo imperfecto. Nexos (406): 33-35.

Schedler, Andreas. 2004. ¿Qué es la rendición de cuentas? México: Instituto Federal de Acceso a la Información.

Secretaría de la Contraloría General. 2011. Lista de servidores públicos sancionados por la Secretaría de la Contraloría General. http://www.cgeson.gob.mx/servicios/rsp/sanc_listado.asp? offset $=0$ (28 de septiembre de 2011).

Ugalde, Luis Carlos. 2003. La rendición de cuentas en los gobiernos estatales y municipales. México: ASF. 


\section{Anexo}

Disposiciones constitucionales sobre la revisión de la cuenta pública

\begin{tabular}{|c|c|c|}
\hline $\begin{array}{l}\text { Disposición } \\
\text { jurídica }\end{array}$ & Texto constitucional & Comentario \\
\hline $\begin{array}{l}\text { CPES, artículo 79, } \\
\text { fracción VII }\end{array}$ & $\begin{array}{l}\text { El Ejecutivo del estado está obligado a } \\
\text { presentar anualmente ante el Congreso, } \\
\text { "en la primera quincena del segundo } \\
\text { periodo de sesiones ordinarias, la cuenta } \\
\text { de gastos del año anterior.” }\end{array}$ & $\begin{array}{l}\text { Puesto que el segundo } \\
\text { periodo de sesiones } \\
\text { ordinarias del Congreso } \\
\text { comienza el } 1 \text { de abril y } \\
\text { finaliza el } 30 \text { de junio, el } \\
\text { gobernador debe presentar } \\
\text { ante éste la cuenta pública } \\
\text { del año anterior entre el } 1 \\
\text { y } 15 \text { del mes de abril del } \\
\text { año inmediato siguiente }\end{array}$ \\
\hline CPES, artículo 42 & $\begin{array}{l}\text { "El Congreso del Estado, destinará el } \\
\text { segundo período de sesiones } \\
\text { preferentemente a examinar las cuentas } \\
\text { públicas del año anterior y a calificarlas } \\
\text { dentro de los cinco meses siguientes } \\
\text { a partir de la fecha límite para su } \\
\text { presentación ante el Congreso." }\end{array}$ & $\begin{array}{l}\text { Esto es, que el Congreso } \\
\text { tiene hasta el } 15 \text { de } \\
\text { septiembre para cumplir } \\
\text { con la obligación de } \\
\text { examinar y calificar las } \\
\text { cuentas públicas }\end{array}$ \\
\hline $\begin{array}{l}\text { CPES, artículo } 42 \text {, } \\
\text { fracción xxv, } \\
\text { primera parte }\end{array}$ & $\begin{array}{l}\text { El Congreso tendrá facultades: "Para revisar } \\
\text { anualmente las Cuentas Públicas del Estado } \\
\text { del año anterior que deberá presentar } \\
\text { el Ejecutivo y revisar y fiscalizar las de los } \\
\text { Municipios que deberán presentar los } \\
\text { Ayuntamientos." }\end{array}$ & $\begin{array}{l}\text { Llama la atención el empleo } \\
\text { de diferentes verbos para } \\
\text { referirse a la cuenta estatal } \\
\text { y a la municipal que allí } \\
\text { se hace, pues mientras las } \\
\text { cuentas públicas del estado } \\
\text { se revisan, las cuentas públicas } \\
\text { municipales se revisan } \\
\text { y se fiscalizan }\end{array}$ \\
\hline $\begin{array}{l}\text { CPES, artículo } 42 \text {, } \\
\text { fracción xxv, } \\
\text { segunda parte }\end{array}$ & $\begin{array}{l}\text { "La revisión de las Cuentas Públicas tendrá } \\
\text { por objeto conocer los resultados de la } \\
\text { gestión financiera, comprobar si se ha } \\
\text { ajustado a los criterios señalados en los } \\
\text { presupuestos aprobados en los programas, } \\
\text { a cuya ejecución se hayan asignado los } \\
\text { recursos presupuestados." }\end{array}$ & $\begin{array}{l}\text { No queda claro si el objeto } \\
\text { señalado aplica para las dos } \\
\text { esferas de gobierno, estatal } \\
\text { y municipal, o si "conocer" } \\
\text { es para el estado y } \\
\text { "comprobar" es para los } \\
\text { municipios }\end{array}$ \\
\hline $\begin{array}{l}\text { CPES, artículo } 42 \text {, } \\
\text { fracción xxv, } \\
\text { tercera parte }\end{array}$ & $\begin{array}{l}\text { "Si de la glosa aparecieren discrepancias } \\
\text { entre las cantidades ejercidas, las partidas } \\
\text { aprobadas y las metas alcanzadas, o no } \\
\text { existiere exactitud y justificación de gastos } \\
\text { hechos, se determinarán las responsabilidades } \\
\text { de acuerdo con la Ley." }\end{array}$ & $\begin{array}{l}\text { El texto constitucional } \\
\text { estatal es lacónico sobre la } \\
\text { posibilidad de aplicar } \\
\text { castigos y sanciones a } \\
\text { quienes hayan incumplido } \\
\text { con sus obligaciones en } \\
\text { el manejo y uso del } \\
\text { presupuesto público. Se hace } \\
\text { uso impersonal del verbo } \\
\text { "determinar", puesto que } \\
\text { no se especifica quién es el } \\
\text { que determina las } \\
\text { responsabilidades en la } \\
\text { fiscalización de los gastos, y } \\
\text { menos aún quién sanciona } \\
\text { los abusos cometidos por los } \\
\text { funcionarios de gobierno }\end{array}$ \\
\hline
\end{tabular}




\begin{tabular}{|c|c|c|}
\hline $\begin{array}{l}\text { Disposición } \\
\text { jurídica }\end{array}$ & Texto constitucional & Comentario \\
\hline $\begin{array}{l}\text { CPES, artículo } \\
\text { 144, fracción I: } \\
\text { Responsabilidad } \\
\text { política }\end{array}$ & $\begin{array}{l}\text { "Responsabilidad Política, determinada } \\
\text { mediante Juicio Político, cuando el servidor } \\
\text { público, en el ejercicio de sus funciones, } \\
\text { incurra en actos u omisiones graves que } \\
\text { redunden en perjuicio de los intereses } \\
\text { públicos fundamentales o de su buen } \\
\text { despacho." }\end{array}$ & $\begin{array}{l}\text { La responsabilidad política } \\
\text { se determina mediante } \\
\text { juicio político realizado por } \\
\text { el Congreso del estado. No } \\
\text { está claro si la corrupción o } \\
\text { la malversación de fondos } \\
\text { entren en la categoría de } \\
\text { "actos graves" para ser } \\
\text { causal de juicio político. } \\
\text { Entonces, el fuero político } \\
\text { puede significar inmunidad } \\
\text { legal }\end{array}$ \\
\hline $\begin{array}{l}\text { CPES, artículo } \\
\text { 144, fracción II: } \\
\text { Responsabilidad } \\
\text { penal }\end{array}$ & \begin{tabular}{|l|} 
"Tratándose de delitos por cuya comisión \\
el autor obtenga un beneficio económico \\
o cause daños o perjuicios patrimoniales, \\
las sanciones deberán graduarse de acuerdo \\
con el lucro obtenido y con la necesidad de \\
satisfacer los daños y perjuicios causados \\
por esta conducta ilíita. Las sanciones \\
económicas no podrán exceder de tres \\
tantos de los beneficios obtenidos o de los \\
daños y perjuicios causados. \\
Las leyes penales determinarán los casos y \\
circunstancias en los que se deba sancionar \\
penalmente por causa de enriquecimiento \\
ilííito a los servidores públicos que durante \\
el tiempo de su encargo o por motivos del \\
mismo, por sí o por interpósita persona, \\
aumenten substancialmente su patrimonio, \\
adquieran bienes o se conduzcan como \\
dueños sobre ellos, cuya procedencia lícita \\
no pudiesen justificar. Las leyes sancionarán \\
con el decomiso y con la privación de la \\
propiedad de dichos bienes, además de las \\
otras penas que correspondan.”
\end{tabular} & $\begin{array}{l}\text { La responsabilidad penal } \\
\text { es regulada por la Ley de } \\
\text { Responsabilidades de los } \\
\text { Servidores Públicos del } \\
\text { Estado y de los Municipios } \\
\text { y por el Código Penal del } \\
\text { Estado de Sonora } \\
\\
\\
\\
\end{array}$ \\
\hline $\begin{array}{l}\text { CPES, artículo } \\
\text { 144, fracción II: } \\
\text { Responsabilidad } \\
\text { administrativa }\end{array}$ & \begin{tabular}{|l|} 
"La responsabilidad administrativa es \\
exigible a los servidores públicos cuando \\
éstos incurran en actos u omisiones que \\
afecten la legalidad, honradez, lealtad, \\
imparcialidad y eficiencia que deban \\
observar en el desempeño de sus empleos, \\
cargos o comisiones. Las sanciones \\
aplicables a esta forma de \\
responsabilidad, además de las que \\
señalen las leyes, consistirán en suspensión, \\
destitución e inhabilitación del servidor \\
público, así como en sanciones económicas, \\
que deberán establecerse de acuerdo con \\
los beneficios obtenidos por el responsable \\
y con los daños y perjuicios patrimoniales \\
causados por sus actos u omisiones, pero \\
no podrán exceder de tres tantos de los \\
beneficios obtenidos o de los daños \\
y perjuicios causados."
\end{tabular} & \begin{tabular}{|l|} 
En estas disposiciones no \\
se establece el criterio de \\
reparación del daño causado \\
ni se aprecia el principio de \\
proporcionalidad entre la \\
culpa y la sanción aplicada. \\
El texto parece dar pie para \\
que se aplique la destitución \\
o suspensión temporal como \\
sanción o castigo para la \\
malversación de fondos \\
\\
\end{tabular} \\
\hline
\end{tabular}




\begin{tabular}{|c|c|c|}
\hline $\begin{array}{l}\text { Disposición } \\
\text { jurídica }\end{array}$ & Texto constitucional & Comentario \\
\hline $\begin{array}{l}\text { CPES, artículo 67, } \\
\text { inciso F. Reforma } \\
\text { publicada en el } \\
\text { B. O., el } 11 \text { de } \\
\text { julio de } 2005\end{array}$ & $\begin{array}{l}\text { "Es atribución del Instituto Superior } \\
\text { de Auditoría y Fiscalización: } \\
\text { F. Investigar los actos u omisiones relativos a } \\
\text { irregularidades o conductas ilícitas } \\
\text { en el ingreso, egreso, manejo, custodia y } \\
\text { aplicación de recursos públicos, pudiendo, } \\
\text { para este efecto, realizar todas las diligencias } \\
\text { que resulten conducentes; incluyendo } \\
\text { visitas domiciliarias a particulares que } \\
\text { hubiesen fungido como proveedores de } \\
\text { bienes o servicios a la autoridad estatal } \\
\text { o municipal, con el exclusivo propósito } \\
\text { de compulsar las transacciones } \\
\text { correspondientes y la documentación } \\
\text { que las sustente, en los términos y con } \\
\text { las formalidades previstas para los cateos." }\end{array}$ & $\begin{array}{l}\text { La Constitución del estado } \\
\text { fue reformada en 2005, a fin } \\
\text { de ajustarse a los cambios y } \\
\text { mejoras en la fiscalización } \\
\text { que se habían hecho a nivel } \\
\text { federal, y sustituir la cmH } \\
\text { por el IsAF (Boletín Oficial no. } \\
\text { 3, sección 2, } 11 \text { de julio de } \\
\text { 2005). El punto medular } \\
\text { de esta reforma consistió } \\
\text { en la adición del artículo } \\
67 \text { al texto constitucional, } \\
\text { el cual declara la creación } \\
\text { del nuevo órgano técnico } \\
\text { del Congreso, sus } \\
\text { características y } \\
\text { atribuciones específicas }\end{array}$ \\
\hline $\begin{array}{l}\text { CPES, artículo 67, } \\
\text { inciso G. } \\
\text { Reforma } \\
\text { publicada en el } \\
\text { B. O., el } 11 \text { de } \\
\text { julio de } 2005\end{array}$ & $\begin{array}{l}\text { “Es atribución del Instituto Superior } \\
\text { de Auditoría y Fiscalización: } \\
\text { G. Determinar y ejecutar las medidas } \\
\text { conducentes a la recuperación de los daños } \\
\text { y perjuicios que afecten al erario por el uso } \\
\text { indebido o equivocado de recursos } \\
\text { públicos, fincando directamente a los } \\
\text { responsables las indemnizaciones } \\
\text { correspondientes y, en su caso, denunciar } \\
\text { ante las autoridades competentes las } \\
\text { responsabilidades administrativas y el o los } \\
\text { delitos que presumiblemente aparezcan } \\
\text { cometidos; de todo lo cual informará al } \\
\text { pleno del Congreso por conducto de la } \\
\text { Comisión referida en la fracción xxxI BIS } \\
\text { del artículo } 64 \text { de esta Constitución.” }\end{array}$ & $\begin{array}{l}\text { Establece la facultad } \\
\text { resarcitoria del ISAF }\end{array}$ \\
\hline
\end{tabular}

Fuente: Constitución Política del Estado de Sonora. http://www.congresoson.gob.mx/ Leyes_Archivos/doc_7.pdf (25 de abril de 2012). 